\title{
0 Projeto Mais Médicos para o Brasil e a construção de mitos:
}

\author{
uma leitura bartheana
}

Giovanni Gurgel Aciole $e^{(a)}$

Aciole GG. The More Doctors for Brazil Project and the construction of myths: a Barthean reading. Interface (Botucatu). 2017; 21(Supl.1):1157-68.

The aim of the The More Doctors for Brazil Project (MDBP) is to supply human resources to the Brazilian National Health System by improving the infrastructure of the healthcare network; expanding educational reforms in in medical courses and residencies; and supplying physicians to vulnerable areas. The implementation of the MDBP faced strong opposition, especially from Brazilian medical institutions. Inspired by the concept of "myth," the present study conducted a reading of the discourse used by the Brazilian Federal Board of Medicine to support its arguments, by analyzing editions of the Medicina newletter published by the Board in the first 24 months of the project's implementation. The myth reveals how discursive practices introduce allegories into the collective imagery that define ideological spaces and enable an analysis of the process of social dispute and the historical conditions behind the formulation and implementation of a government program.

Keywords: Health policy. Planning and administration. Government programs. Government Health Plans. Primary Health Care. Brazilian National Health System.
O Projeto Mais Médicos para o Brasil (PMMB) tenciona prover recursos humanos para o Sistema Único de Saúde por meio da melhoria da infraestrutura da rede de saúde; da ampliação das reformas educacionais dos cursos de Medicina e residência médica; e da provisão de médicos para áreas vulneráveis. A implantação do projeto enfrentou reações contrárias à proposta, envolvendo principalmente as instituições médicas do país. Inspirados no conceito de mito, realizamos uma leitura dos discursos com que o Conselho Federal de Medicina sustentou o debate, por meio da análise do Jornal Medicina durante os primeiros 24 meses da implantação do PMMB. O mito é revelador de como práticas discursivas introduzem no imaginário coletivo alegorias que demarcam espaços ideológicos e permite analisar o processo de disputa social e das condições históricas de formulação e implantação de um programa governamental.

Palavras-chave: Políticas públicas. Planejamento e administração em Saúde. Programas governamentais. Atenção Primária à Saúde. Sistema Único de Saúde.

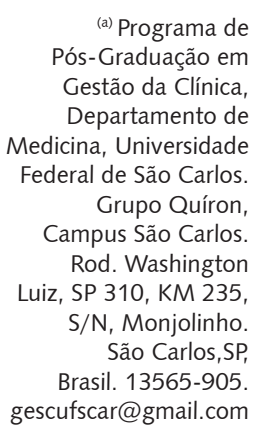

(a) Programa de Pós-Graduação em Gestão da Clínica, Departamento de Medicina, Universidade Federal de São Carlos. Grupo Quíron, Campus São Carlos. Rod. Washington Luiz, SP 310, KM 235,

$\mathrm{S} / \mathrm{N}$, Monjolinho. São Carlos, $\mathrm{SP}$, Brasil. 13565-905. gescufscar@gmail.com 


\section{Introdução}

A alocação e fixação de profissionais da Saúde são elementos de iniquidade social, penitenciando populações como "destinadas" a não ter acesso aos serviços de saúde; e obstáculos para o fortalecimento dos sistemas de saúde nos países afetados ${ }^{1-3}$. Atualmente, mais de quatrocentos municípios brasileiros estão desprovidos de médicos, tornando este fato um problema prioritário para a gestão do Sistema Único de Saúde (SUS). Estudo do Instituto de Pesquisas Econômicas Aplicadas (Ipea), em 2011, revelou a percepção da população em relação à escassez de profissionais médicos: $58,1 \%$ dos 2.773 entrevistados disseram que a falta de médicos é o principal problema do SUS ${ }^{4}$.

As tentativas de ordenamento dessa área consideram que a Estratégia de Saúde da Família (ESF) é capaz de ampliar a resolutividade e de impactar na situação de saúde das pessoas e coletividades, mediante a reorientação do modelo assistencial ${ }^{4}$, mas ainda não foi capaz de responder aos desafios colocados, e permanece o hiato em incorporá-la à ação política efetiva ${ }^{4,5-7}$. Um dos nós críticos para o sucesso da ESF são os vazios assistenciais, locais que não conseguem prover e fixar profissionais de saúde na atenção básica, em especial médicos, não garantindo acesso aos serviços básicos de saúde pela população $0^{8-11}$. A rotatividade de profissionais, principalmente médicos, coloca-se como entrave ao desenvolvimento de atenção integral à saúde ${ }^{12}$, o que potencializa a necessidade de ações no âmbito da gestão do trabalho e da educação na saúde ${ }^{13}$.

Mobilizado por essa questão, em 2013, o Governo Federal instituiu o Projeto Mais Médicos para o Brasil (PMMB), com a finalidade de alocar médicos nos vazios assistenciais e enfrentar os problemas de acesso da população vulnerável às ações e serviços de saúde com qualidade. Três anos depois, faz-se necessário indagar a sua dimensão simbólica, isto é, em que medida afetou/tem afetado o imaginário social e cultural; e o que agregou para as ações na atenção básica e, consequentemente, para o SUS, particularmente em um de seus focos mais agudos: a produção do acesso/acolhimento a populações desassistidas. A intenção deste artigo é colocar em relevo as razões e motivações lógico-discursivas no debate inicial de implantação e a mitologia que alimentaram em torno e em razão desse projeto.

\section{Notas sobre o conceito de mito}

Utilizamos o conceito de "mito", formulado por Roland Barthes ${ }^{14}$. O mito é um discurso alegórico ou uma narrativa lendária; o meio para um fim; a imposição de uma ideologia, uma visão de classe, de uma visão parcial de mundo que se pretende universalizar. O mito é um sistema de comunicação, uma mensagem. Pode ser um objeto, um conceito ou uma ideia: ele é um modo de significação, uma forma, que pode assumir diversos aspectos: texto, imagem, fotografia, espetáculo, publicidade. 0 mito é uma mensagem, e todas as formas que pode assumir são de apoio à forma mítica. O mito não pode se definir pelo seu objeto nem pela sua matéria, pois qualquer matéria pode ser arbitrariamente dotada de significação. Uma flecha apresentada para significar uma provocação é também uma fala; uma fotografia será considerada fala exatamente como um artigo de jornal. A imagem e a escrita, porém, não solicitam o mesmo tipo de consciência; e a própria imagem propõe diversos modos de leitura. Uma imagem pode se transformar em escrita, e vice-versa, a partir do momento em que é significativa; na forma escrita, contudo, exige uma léxis, isto é, concatenar um discurso racional e lógico, de nexos significantes e significados. Entender-se-á por linguagem, portanto, discurso, fala, toda unidade ou toda síntese significativa.

O mito é um valor, não tem a verdade como sanção: nada o impede de ser um perpétuo álibi: o sentido existe sempre para apresentar a forma; a forma existe sempre para distanciar o sentido. O mito tem que ser, simultaneamente, invisível e natural, porque a sua identificação apontaria sempre para uma tentativa de manipulação. O mito não é nem uma mentira nem uma confissão: é uma distorção. Não interessa a interdição, mas a exposição. E o mais importante: o mito precisa de fraseologia e nela os slogans têm um papel insubstituível. A frase feita ajuda a apreender e a justificar o mundo de uma maneira muito mais simples, permitindo uma constatação imediata e sem maiores reflexões.

O mito naturaliza a história e engessa o mundo, de forma a impedir a transformação. Presta-se, portanto, a um uso conservador do status quo. É aí que ele é essencial: bem-alimentado, lustroso, 
expansivo, falador, inventa-se continuamente. Apodera-se de tudo: justiças, morais, estéticas, diplomacias, artes domésticas, literatura, espetáculos. Enfim, mito e ideologia são parentes próximos: entrelaçam-se, confundem-se e são categorias incontornáveis para desmascarar o processo de legitimação da sociedade burguesa. O mito é produto de uma classe social dominante que acaba por ser incorporado pelos membros da classe dominada, mesmo quando vai contra os seus próprios interesses. Produzir essa aceitação - pela naturalização - é a sua função. Naturalizar a história é fazer com que os indivíduos aceitem os fatos sociais como naturais, de modo a eclipsar o papel da história e suas implicações sociais.

Uma forma de analisar os discursos é enxergar neles a mitologia que transportam. Um livro, um artigo, um filme, uma fotografia, uma imagem são veículos de mitos a depender do contexto em que são vistos ou lidos, e dos usos que podem ganhar de acordo com quem os utiliza.

Existe, contudo, uma linguagem que não é mítica, que é a linguagem do homem produtor, isto é, a linguagem do homem que age para a transformação do real, e não para conservá-lo: sempre que ele associa a sua linguagem à produção das coisas, a metalinguagem é reenviada a uma linguagemobjeto, e o mito torna-se impossível. Por meio dele se pode traçar a disputa pela realização plena da política. Quanto a esta, a definição semiológica do mito se completa na sociedade burguesa, porque nela o mito é uma fala despolitizada. Se o mito é uma fala despolitizada, existe pelo menos uma fala que se opõe ao mito: aquela que permanece política, isto é, a que não naturaliza a história e nem a coagula na imobilidade temporal.

A retórica dos mitos constitui um conjunto de figuras fixas, estabelecidas, insistentes, nas quais vêm se encaixar as formas dos significantes, a saber: a vacina, com a qual o imaginário coletivo é imunizado pela inoculação de um mal reconhecido e defendido contra o risco de uma subversão generalizada; a omissão da história, por meio da qual esta se evapora, desaparece silenciosamente: e dela podemos usufruir sem nos questionarmos sobre a sua origem, que só pode provir da eternidade, inacessível ao agir responsável dos homens; e a identificação, pela qual o outro é reduzido ao mesmo. Os espetáculos, os tribunais, locais onde pode acontecer a exposição do outro, transformam-se em espelhos; a tautologia, que consiste em definir o mesmo pelo mesmo, é um refúgio para quem não encontra uma explicação, e fundamenta um mundo morto, um mundo imóvel; o ninismo, que consiste em colocar dois contrários e equilibrar um com o outro, de modo a poder rejeitar os dois ("Não quero nem isto nem aquilo"); a quantificação da qualidade, que, reduzindo toda qualidade a uma quantidade, torna o mito econômico no que diz respeito à inteligência: compreende o real por um preço reduzido ${ }^{14}$.

Como leitores de mitos, fizemos sua exploração nas edições do Jornal Medicina, portavoz das posições do Conselho Federal de Medicina (CFM): autarquia federal de regulamentação da prática profissional a que todos os médicos obrigatoriamente devem se vincular para registro, diferentemente das outras organizações (sindicatos e associações de especialidades), cujo vínculo é opcional. Tal Conselho envia seu jornal mensalmente ao exército de profissionais cadastrados no país. Perseguindo captar as manifestações oficiais, elegemos as seções "Editorial", "Mensagem do Presidente" e a matéria de capa da edição mensal. Os resultados estão apresentados a seguir, em um acompanhamento do desenvolvimento da ação governamental às manifestações oficiais do Conselho.

\section{A ação do governo}

O PMMB inaugura uma ação governamental que conjuga esforços inauditos de mudança e transformação do existente. Os objetivos desse projeto são diminuir a carência de médicos nas regiões prioritárias para o SUS; fortalecer a prestação de serviços na Atenção Básica à Saúde; aprimorar a formação médica no país e proporcionar maior experiência no campo de prática médica durante o processo de formação; ampliar a inserção do médico em formação nas unidades de atendimento do SUS, desenvolvendo seu conhecimento sobre a realidade da saúde da população brasileira; fortalecer a política de educação permanente com a integração ensino-serviço, por meio da atuação das instituições de educação superior na supervisão acadêmica das atividades desempenhadas pelos médicos; promover a troca de conhecimentos e experiências entre profissionais da saúde brasileiros e 
médicos formados em instituições estrangeiras; aperfeiçoar médicos para atuação nas políticas públicas de saúde do país e na organização e funcionamento do SUS; e estimular a realização de pesquisas aplicadas ao SUS ${ }^{15}$.

A proposta de provimento e fixação de profissionais de saúde, combinada com medidas de apoio tutorial e formação para o SUS, resulta em uma configuração na qual se entrelaçam questões referentes à formação, gestão e regulação do trabalho e dos trabalhadores da saúde, especialmente a partir do avanço da ESF, que trouxe consigo inúmeros desafios a esse campo, como o descompasso entre o ensino e as necessidades da Atenção Básica. Já podemos apontar aí mais uma das linhas mestras a partir das quais os mitólogos reagirão à proposta governamental. Trata-se de a um só tempo convulsionar os territórios pacificados em que transitavam, até então, confortáveis arranjos de interesses das agendas que envolvem a educação médica no Brasil.

Em boa medida, a disparidade regional na distribuição de postos de trabalho na Atenção Básica em todo o país se sustenta no contexto do desenvolvimento macroeconômico em que já despontava um cenário de crise ainda com poucos reflexos na empregabilidade e proteção ao emprego para a categoria médica. Tratava-se de aliar a um processo de incremento econômico e redução das desigualdades regionais avanços em políticas sociais, como acesso a saúde e serviços. Esses dois eixos argumentativos evidenciam a estratégia de enfrentamento da pauta abraçada pelas entidades médicas em direção oposta, referente ao fato de que não faltavam médicos no país, como poderemos constatar mais adiante.

Perante esse mito repetido há décadas pelas entidades médicas, o governo demonstra o cuidado de buscar informações e dados comparativos, de modo a contornar ou a contradizer as posições difundidas pelas entidades médicas. A estratégia era, porém, mais complexa: mostrava que, em um contexto de mínimos índices de desemprego e com a economia fortalecida, se não se podia falar em desemprego médico, a existência de claros contingentes de posto de trabalho em todas as regiões do país - principalmente em regiões carentes, como o semiárido nordestino e a Amazônia legal desmontava cabalmente a tese da suficiência de médicos. Não só estavam mal distribuídos em todo o país, mas também eram insuficientes para preencher todos os postos de trabalho. O governo buscou capilarizar o discurso em vários públicos, não só os políticos/institucionais, como gestores, prefeitos e suas associações, mas também o público acadêmico, levando o debate também para o interior das universidades.

Outra estratégia foi a inserção da proposta emergencial como parte de um conjunto de ações governamentais que estruturavam a política de provimento e fixação de médicos em um leque que incluía a distribuição e alocação, passava pela questão da infraestrutura, por meio de várias linhas de fomento e melhoria da qualidade da atenção básica, e seguia na direção da transformação na formação para o SUS. Estruturava-se um conjunto de políticas que conferia ao PMMB uma robustez em que se destacam a ampliação da formação de médicos no país e a abertura de novas escolas médicas, direcionadas conforme prioridades regionais. Em 2012, um programa voltado à expansão de vagas do ensino médico nas instituições federais de ensino superior (IFES) estabeleceu a meta de criação de 1.615 vagas em cursos de Medicina existentes ou novos cursos nas universidades federais, durante os anos de 2013 e $2014^{16}$. Para a criação dos novos cursos, foi proposto um projeto de criação de residência médica nos mesmos locais dos novos cursos, como forma de apoio. No momento da redação deste artigo, estava em curso o processo de autorização das novas vagas e a relação de cidades e regiões contempladas parece atender ao disposto na intenção governamental.

\section{A mitologia no discurso da principal entidade médica}

A organização da corporação médica no Brasil a torna uma corporação especial nas profissões de origem liberal, de grande reconhecimento na trama social, pertencente às elites e de imagem cultural associada à produção científica, técnica e acadêmica. Tendo como perspectiva de trabalho a produção de certo modo de cuidar da vida e da saúde do ser humano a corporação médica tem ocupado um lugar central na organização do processo de trabalho em saúde, dentro dos processos de produção da assistência à doença e da proteção à saúde. Para nossos fins e propósitos, tomamos como voz das 
posições dos médicos o Conselho Federal de Medicina, especialmente por ser a autarquia federal de regulamentação da prática profissional a que todos os médicos obrigatoriamente devem se vincular para registro.

Uma manifestação reiterativa da entidade - em edições de março, abril, junho a agosto, novembro e dezembro de 2013; janeiro, março a junho de 2014; e fevereiro, abril, maio, agosto e novembro de 2015 - é a denúncia da incompetência do governo e da crise na saúde, expressa no caos dos hospitais públicos, no descaso com a infraestrutura, no fechamento de leitos e na insuficiência de recursos. Um discurso monotemático que mitifica a questão do processo social de construção do SUS e naturaliza sua situação real em termos dos mitos de caos, crise, incompetência, subfinanciamento e falta de recursos e de infraestrutura para o trabalho médico. O mito se constrói afirmando que:

[...] continuam faltando leitos, materiais, equipamentos e medicamentos, a um ponto tal que a maioria dos médicos brasileiros contratados para o programa desistiu, logo em seu primeiro dia de trabalho [...]. Frequentemente, estetoscópio e caneta eram os únicos equipamentos que dispunham para salvar vidas ${ }^{17}$.

Ao lado disso, há a denúncia de um governo inoperante e iníquo, injusto com os médicos, que completou dez anos no poder em 2013:

[...] fechou mais de 40 mil leitos hospitalares, 280 hospitais e 47 mil vagas em unidades básicas, tornando a saúde pública brasileira um exemplo de descaso e má gestão. [...] [Não bastasse] agora aponta o dedo acusador para os médicos e instituições que os representam, dizendo que são contra a saúde do povo [...] num momento em que em todo o país se clama por serviços públicos decentes, impostos que não sejam extorsivos e o fim da impunidade para os corruptos. ${ }^{17}$

O tema volta à tona na edição do lançamento da Medida Provisória (MP) que instituía o provimento de vagas para médicos. Alegando base científica para fazer frente à posição do governo, o jornal dá publicidade ao estudo "Demografia médica no Brasil 2: cenário e indicadores de distribuição" 18, que permitia reconhecer a existência das mesmas disparidades regionais identificadas pelo governo, mas a recortava segundo os interesses ideológicos subjacentes. O titulo da matéria não deixa dúvidas: "Distribuição desigual atinge SUS e regiões com piores indicadores"18. Trata-se de um discurso generalizador e opaco que mistura questões setoriais com macroeconômicas e fiscais sem argumentar diretamente com o diagnóstico e as justificativas governamentais.

Frente à insistência do governo na importação de médicos, o jornal segue ecoando o que chamou de interesses "imediatistas" para o SUS ${ }^{19}$. Mesmo dizendo não ser contra a medida de importação dos médicos, ressalva que se submetam à revalidação dos seus diplomas e questiona se os médicos oriundos de outras realidades reúnem condições em termos de conhecimento e habilidades técnicas para trabalhar em locais precários, sem infraestrutura adequada de insumos e de equipamentos, e interroga como assegurariam a seus pacientes acesso a exames e condutas necessários, distantes dos médios e grandes centros. Traz a tona o mito da qualificação e da precariedade material do SUS, sempre a situar ideologicamente o SUS nos rincões da precariedade, da falta e da insuficiência. Também é taxativo: não faltam médicos e não precisamos importar nenhum, nem abrir escolas. Dados técnicos rebatem falácias do governo, incapaz de implantar medidas de médio e longo prazo para evitar a migração interna e o tropismo médico de se alojar em regiões centrais e mais ricas do país.

Longe de falta de médicos, os tínhamos em excesso: descobrimos tal informação na edição que expressou a preocupação com a "falta" de critérios para a entrada de médicos estrangeiros no país, sempre argumentando que o principal prejudicado seria o SUS. Além disso, apontavam-se contradições na ação governamental que autorizava abertura de novas vagas de Medicina em regiões sem qualquer critério, ou reconhecidamente sem necessidade premente. Na ação planejadora se rebate o mito da inexistência de critérios $^{19}$.

$\mathrm{Na}$ edição seguinte ${ }^{20}$, ecoa a mobilização da categoria em defesa do SUS, amplamente alimentada pelos slogans que afirmam que não precisamos de mais médicos, pois já temos escolas demais, e o que 
falta é qualidade. O apelo, novamente, é direto: a responsabilidade pelas mazelas da saúde não pode ser transferida aos médicos, mas sim à falta de financiamento do setor e à ausência de uma política de Estado na assistência em saúde, capaz de distribuir e valorizar os profissionais da área. De novo, mitificam-se as mazelas de gestão e insuficiências de financiamento. Nenhuma questão referente à distribuição dos profissionais ou à sua alocação regional entra na equação dos problemas do SUS, com a ressalva feita pelo jornal de que a mobilização pretendeu discutir os critérios para a entrada de médicos estrangeiros a trabalho no Brasil e sensibilizar parlamentares para a criação da carreira médica de Estado como leitmotiv, o que levou cerca de quinhentos médicos e acadêmicos a Brasília ou, mais exatamente, aos salões e auditórios do Poder Legislativo.

Uma inflexão da entidade médica em relação ao PMMB foi a de apresentar uma proposta alternativa, que chamou de programa de interiorização. Combinando ressalvas interessantes ao processo de alocação, de novo sem acatar seu caráter de excepcionalidade, ataca pontos essenciais do que seria uma ação houdiniana do governo: nosso baixo padrão de financiamento do SUS, nossa precária infraestrutura dos serviços públicos e a inexistência de uma validação prévia dos diplomas dos "importados"21.

Muito embora apresente questões que reclamem um tratamento mais profundo, o posicionamento e a narrativa política da entidade apenas efetivaram o simplismo de reclamar mais verbas para a saúde, criticar a precariedade da infraestrutura existente nos rincões mais distantes do país e, especialmente, ser contra a entrada de médicos estrangeiros sem a revalidação de seus diplomas. E outro mito é lançado: não somos contra a vinda de médicos, somos contra a forma como está sendo feita pelo governo ${ }^{22}$. Pois as entidades médicas nada têm de corporativistas ou xenófobas. Serão bem-vindos todos os médicos estrangeiros e brasileiros formados em outros países, desde que provem em exames do nível do atual Revalida (criado pelo próprio governo, em 2010) que dão conta do recado.

As razões em defesa do exame são mitologicamente ilustrativas. No Brasil, não há meio médico. Quem faz Medicina tem que resolver os desafios em todos os níveis de complexidade: de uma diarreia a um procedimento de emergência. Mas o que acontece quando a maioria prefere tratar da emergência em Unidades de Terapia Intensiva e não das diarreias nos rincões? Trazer médicos que vão apenas fazer consultas em postos de saúde é, no mínimo, um paliativo.

E o que acontece se num desses rincões o Seu João tiver uma crise aguda de apendicite? O prefeito e o médico do posto o colocarão numa ambulância rumo ao município vizinho? Esse embuste tem nome: pseudoassistência. E quem concorda em fazer parte dessa armação é um pseudomédico 22 .

A próxima ação do governo foi editar uma MP que criou um regime especial de registro e autorização da prática médica para o Ministério da Saúde, restrito ao escopo das práticas assistenciais incluídas no PMMB. A resposta do CFM não se fez esperar e ganhou as ruas na forma de manifestações em caminhadas, atos e passeatas. Expressivos são os motivos declarados: a entidade não aceita a decisão do governo e se coloca contra o regime especial. Os apelos são evidentes: os protestos em todo o país não deixaram dúvidas. Na primeira semana de julho, o país se vestiu de branco: milhares de médicos, professores, residentes e estudantes de Medicina foram às ruas protestar contra a decisão do Governo Federal de promover a importação de médicos formados no exterior sem a devida aprovação pelo Revalida em seus moldes atuais ${ }^{23}$.

Um país vestido de branco foi às ruas dizer ao governo que este não escuta os anseios da saúde de seu povo. Difícil encontrar imagem mítica melhor, se ainda agregaram os apoios institucionais e simbólicos de advogados e odontólogos e se assistiu à aprovação, pelo Congresso, após longos 11 anos de tramitação, da lei que institui o Ato Médico, medida corporativa de defesa do mercado para a categoria ${ }^{24}$ e que passa a depender da sanção presidencial, justamente da presidente questionada pelos próprios médicos de não respeitá-los e de massacrá-los perante a população brasileira.

Essa tensão se expressa em um editorial assinado em conjunto por várias entidades representativas dos médicos, afetadas pelas propostas de abertura de novas vagas em graduação em Medicina e pelas alterações na oferta e distribuição de vagas para as residências médicas em todo o território 
nacional. Por isso mesmo, um Comitê Nacional de Mobilização das Entidades Médicas reuniu o CFM, a Associação Médica Brasileira (AMB), a Associação Nacional dos Médicos Residentes (ANMR), a Federação Nacional dos Médicos (Fenam) dos sindicatos da categoria e a Federação Brasileira de Academias de Medicina (FBAM), que é representativa das academias médicas estaduais. Ao longo do jornal, ecoam as mesmas posições: é preciso enfrentar e resistir ao governo e às suas medidas discriminatórias ${ }^{25}$.

Dessa vez, os médicos são mitificados como vítimas e convidados a se solidarizar com óbvia ideologização: o governo nos marginaliza, pois:

[...] virou prática no mundo político a marginalização de médicos, prestadores de serviços e pacientes. [Neste contexto, a proposta significava] um tijolo retirado do alicerce da democracia e da universalização da saúde, um ataque frontal à Constituição e parte da estratégia de criar dois tipos de Medicina no país.

Segundo esse novo mito, as classes mais abastadas continuariam a receber atendimento em uma rede de excelência, com médicos bem treinados, equipamentos de ponta e estrutura de primeiro mundo. A população mais carente, portanto, mais vulnerável, seria condenada a um arremedo de assistência prestada por profissionais formados no exterior sem comprovação de capacidade, por residentes sem preceptoria adequada, em localidades sem estrutura para o atendimento. A simbologia do discurso está, ainda, na ameaçadora imagem de um país dividido segundo dois tipos de Medicina: uma, urbana e metropolitana, com médicos capazes e bem treinados, tecnologia de ponta e estrutura adequada; outra, dos rincões carentes, de povo vulnerável, sofrido e recebedor de uma assistência precária, arremedo de atenção, sem qualidade, sem tecnologia, sem infraestrutura, com médicos pouco capazes ou inabilitados.

O enfrentamento aos efeitos da MP 621 continua com diagnósticos do que considera o descaso do governo na saúde e alertas à população para os riscos da atenção por parte de médicos sem qualificação atendendo em lugares sem condições mínimas de trabalho e de assistência. Sob a singeleza de um título editorial que apregoa "apenas a verdade", as matérias vão prosseguir contra as medidas governamentais, mas ressaltando que nenhuma entidade médica é contra medidas de qualificação e investimento na saúde - exceto a pretendida intenção do governo de fazer o que a MP elenca e autoriza -; pelo contrário, todas defendem a oferta de condições de trabalho e de emprego dignas que beneficiem pacientes, profissionais e gestores. Afinal, o PMMB falha ao oferecer uma solução rasa, de duvidoso efeito e que contraria a legislação: fragilidades que devem ser corrigidas para que retorne aos trilhos do bom senso e da legalidade ${ }^{26}$.

Em setembro, o jornal trouxe notícias da movimentação e dos "acordos" negociados com os parlamentares, para reduzir os prejuízos para a Medicina. Dando ênfase à ideia de que negociar não é oferecer apoio, o jornal envereda na defesa da recuperação da tradição humanista que sempre norteara a profissão. Tece perorações sobre a natureza política da entidade e seus limites, em uma elucidação da missão institucional dos órgãos, criados pela Lei 3.268/57 para defender o bom exercício ético da profissão e atuar firmemente em defesa do atendimento de qualidade para a sociedade, pois:

[...] Estas missões constituem o âmago de suas atuações, as quais vêm sendo exercidas por meio das resoluções emitidas, das ações de fiscalização, dos processos na esfera judicante e, ainda, pelo debate político. [...] [Afinal] os conselhos fazem política, sim, mas no que esse termo tem de mais nobre: definição de estratégias, participação em debates e a tomada de decisões em busca de ganhos efetivos para o coletivo. ${ }^{27}$

Sentindo-se ameaçado pelo PMMB, o CFM alinha outros mitos em sua ressalva: o alto espírito público e a defesa do interesse coletivo que tem como alma. "Qual coletivo?", caberia perguntar. Sobre isso, o texto nada esclarece. Apenas ressalta que não se trata de "defesa corporativa, ou sindical, ou associativa ou para os interesses específicos da categoria, salvo quando os temas em discussão têm indiscutível repercussão na atuação profissional e nas condições de assistência como um todo" 27. 
Como devem trafegar em busca do diálogo, do consenso, da harmonização dos diferentes interesses existentes na sociedade em prol da Saúde e da Medicina, não se pode "esquecer que essas entidades são autarquias públicas, ou seja, são braços do Estado no campo da atuação profissional, mas não governo" 27 . Explicadas as razões pelas quais foram negociar com o governo, aponta-se no fim qual foi a consequência benéfica desse agir negociador havido entre os diferentes braços do Estado: abrir espaços de escuta e intervenção na legislação em discussão no Congresso ${ }^{27}$.

A trégua no diálogo com o braço "esquerdo" do Estado e a crítica construtiva logo viriam à tona, quando o jornal denuncia o subfinanciamento do SUS, que em dez anos deixara de receber a expressiva cifra de 94 bilhões. De novo, colocando a conta nas costas dos governos responsáveis pelo $\mathrm{PMMB}$, o jornal volta a relacionar os gastos em Saúde com a qualidade da atenção médica no país, e a respeito o texto é insofismável acerca das posições da entidade:
A falta de financiamento na saúde tem comprometido o pleno exercício da medicina e, por conseguinte, o efetivo atendimento aos pacientes. Por isso, cabe aos conselhos de medicina cuidar e lutar para a correção desta falha, por meio do acompanhamento do orçamento da Saúde, para mensurar o impacto desse descaso na qualidade da assistência. [...] Sem investimentos, não há como oferecer a infraestrutura e os insumos fundamentais para que os médicos que atuam no Sistema Único de Saúde (SUS) possam ajudar a população. [...] Impede-se que os pacientes tenham acesso aos serviços necessários para realizar a prevenção, o diagnóstico e o tratamento de suas doenças, bem como a leitos, exames e consultas. ${ }^{28}$

Em novembro, a movimentação das entidades as levou aos gabinetes dos juízes superiores para justificar as "ilegalidades" da MP 621. Como autarquias públicas especiais, cabe aos Conselhos de Medicina atuar em defesa do bom exercício profissional, assegurando condições para a atuação dos médicos e da oferta de assistência de qualidade para a população. Por isso, e com base no artigo $2^{\circ}$, da Lei 3.268/57, sobre esta missão, " [...] apresentamos aos leitores a cobertura da audiência pública no Supremo Tribunal Federal (STF) que analisou diferentes aspectos relacionados ao programa Mais Médicos" ${ }^{29}$, em que acusam a irresponsabilidade do governo. Além dessa crítica técnica, teve destaque a leitura jurídica feita pelo representante do Ministério Público do Trabalho: trata-se de uma ação eivada de ilegalidades ${ }^{29}$.

No entanto, a "ilegalidade" foi aprovada no Congresso e virou lei. Diante desse fato, o CFM abre outra frente de disputa: a questão trabalhista envolvida, acusando o governo de ilegalidades e de afrontar o arcabouço de proteção trabalhista. A entidade acusa o governo de santificar os médicos do programa e satanizar a profissão brasileira, quando os médicos importados (em sua maioria, cubanos) não passariam de escravos, ou quase isso, submetidos a um regime de trabalho que os acorrenta à exploração e à precarização de vínculos empregatícios. Inocentes úteis a serviço do repasse de bilhões de reais para marketing e propaganda governamental, agentes do populismo mais bisonho, postergando a adoção de soluções mais efetivas como a carreira de estado, profissionalização da gestão da saúde e, claro, aporte de mais recursos financeiros. Pleno de função despolitizadora, tanto quanto ideológica, o mito se completa nas imagens que correram o país de médicos cubanos sendo vaiados, enxovalhados e agredidos verbalmente em seu desembarque, ao longo das semanas seguintes, por médicos brasileiros.

Enquanto isso, o jornal prossegue asseverando que os médicos brasileiros são os verdadeiros injustiçados na questão, sofrendo agressões gratuitas a uma categoria corresponsável pelos avanços alcançados no país no campo da Saúde Pública, por meio do SUS: sistema tributário da dedicação de milhares de colegas que fazem Medicina em lugares onde falta tudo. O jornal da entidade arremata:

Ao adotar esta injustiça, o governo faz marketing, aproveitando-se da fragilidade da população. Omisso em soluções reais, cria um programa "faz de conta" e atira sobre os médicos a responsabilidade por seu próprio fracasso, para resolver questões que poderiam ser sanadas com outras medidas, como de mais recursos, profissionalização da gestão e criação da carreira de Estado para médicos e profissionais do SUS. ${ }^{28}$ 
[...] Fala-se muito e pouco se faz e os abusos continuam: verbas disponibilizadas são devolvidas aos cofres da União porque não foram gastas e em lugar de modernizar o gerenciamento do sistema, se aposta em medidas midiáticas, como o programa Mais Médicos. ${ }^{28}$

Apesar da anunciada propensão à luta sem fim ("entendemos que o embate em torno deste programa ainda está longe do fim" ${ }^{28}$ ), com a paulatina alocação de médicos nas áreas prioritárias e o equacionamento jurídico e político das principais pendências ou polêmicas; e visto que a sociedade se mostrou insensível a estes efeitos ("a sociedade mostrará que, ao contrário do que afirmam pesquisas tendenciosas, o marketing não tem o poder de influenciar decisões tomadas pelas urnas" ${ }^{28}$ ), o tema vai sofrendo um deslocamento e perde aparecimento mensal, deixando de aparecer nas seções sob análise. Ainda está nas edições de março, junho, agosto a novembro de 2014, e em algum mês de 2015, com a mesma mítica que associa ao programa imagens como as apresentadas, mas sem o mesmo destaque.

O PMMB ganhou ampla aceitação popular; a entidade passou por eleições nacionais e composição de um novo corpo dirigente para o quinquênio 2015-2019; e o tema vem à baila em momentos muito especiais, feitos para acompanhar denúncias pontuais deste ou daquele episódio do projeto. A pauta informativa da entidade permanece focada nos objetos míticos que a tem sustentado, como as ameaças advindas das práticas dos planos de saúde, o aumento das exigências do mercado e as iniciativas das especialidades em seu agir político cotidiano.

\section{Considerações finais}

Decorridos três anos do $\mathrm{PMMB}$, a efervescência política cedeu lugar à normalidade perceptível no desaparecimento desta pauta na imprensa em geral e da entidade médica cujo jornal se examinou, fruto das circunstâncias, do momento histórico e dos processos que mobilizou. Sobretudo, fruto das mitologias cuja produção disparou. Da ação governamental, seu grande mérito é o agir reformador. Pela primeira vez em muitos anos, o governo enfrentou o status quo de que pode mexer em questões como promoção da saúde, prevenção de agravos, mas deixar a oferta e provimento de médicos ao sabor dos interesses dos próprios. Ao afrontar essa dimensão da luta mítico-política, o governo demonstrou que o Estado pode fazer muito mais em relação a organizar/desorganizar o "sistema" do que todos os mercados reunidos. Esse agir desnudou a questão da representação corporativa dos médicos e sua agenda política com a sociedade, ou com a parcela da sociedade a que se volta prioritariamente.

O PMMB mobiliza questões como saber se a solução do SUS passa pela adoção da carreira de Estado; se a consolidação da Atenção Primária como vetor da mudança de modelo assistencial está prestes a eclodir seus potenciais efetivos de ação; se a aposta na centralidade da intervenção pelo provimento e fixação de médicos não é um equívoco conceitual e uma ação reforçadora da centralidade médica como instrumento de mudança nas práticas de saúde; e o que fazer de concreto para não excluir ou "esquecer" de incluir as demais categorias profissionais tão importantes e fundamentais para a consecução de outro objeto mítico que é a integralidade ${ }^{29}$. Há mais questões em aberto!

Quanto ao jornal do CFM, a menção ao projeto foi perdendo destaque de capa e de matérias de capa e cedendo lugar a um "silêncio" editorial. A análise não permitiu identificar fatores ou hipóteses explicativas, exceto a hipótese de que a perda de centralidade editorial e de capa ocorreu na razão direta da consolidação do projeto e da sua ampla aceitação política e social. Também merece menção a mudança de direção ocorrida no fim de 2014, que deve ter aduzido outra pauta política à ação comunicacional da entidade.

A ação reformadora do PMMB parece irreversível e tem abrigado novas semiologias e novas práxis, tanto dos governos sucedâneos quanto das instituições e organizações diretamente afetadas pela ação governamental, entre elas, a dos médicos brasileiros, mas não apenas. É preciso ouvir aqueles que ainda não tiveram oportunidade de se fazer escutar: os outros profissionais, os gestores municipais e, acima de tudo, os usuários beneficiados, direta ou indiretamente, pelo acesso promovido pelo projeto.

Ainda há mitos por emergir, revelar e disputar! 


\section{Referências}

1. Garcia ACP. Gestão do trabalho e da educação na saúde: uma reconstrução histórica e política. [dissertação] [Internet]. Rio de Janeiro: Universidade do Estado do Rio de Janeiro; 2010 [citado 8 Ago 2013]. Disponível em: http://www.obsnetims.org.br/ uploaded/2_5_2013_0_Gestao_trabalho.pdf

2. Roas AC. Experimentos de escolha discreta sobre provimento e fixação de recursos humanos em saúde. [Internet]. In: Anais da $\sigma^{a}$ Jornada Nacional de Economia da Saúde; 2012; Brasília. Brasília: Associação Brasileira de Economia da Saúde; 2012 [citado 8 Ago 2013]. Disponível em: http://abresbrasil.org.br/sites/default/files/poster 21 0.pdf

3. Viana ALD, Dal Poz M. A reforma do sistema de saúde no Brasil e o Programa de Saúde da Família. Physis. 1998; 8(2):11-48.

4. Ministério da Saúde (BR). Secretaria de Gestão do Trabalho e da Educação na Saúde. Seminário nacional sobre escassez, provimento e fixação de profissionais de aaúde em áreas remotas de maior vulnerabilidade. Brasília: SGETS/MS; 2012.

5. Dal Poz M. Entre o prescrito e o realizado: estudo sobre a implantação do SUS no Estado do Rio de Janeiro e sua repercussão na política de recursos humanos em nível municipal. [tese] Rio de Janeiro: UERJ; 1996.

6. Pierantoni CR, França T, Garcia AC, Santos MR, Varella TC, Matsumoto KS. Gestão do trabalho e da educação em saúde. Rio de Janeiro: CEPESC, IMS/UERJ, ObervaRH; 2012.

7. Abreu WL, Assis M. Acesso aos serviços de saúde: abordagens, conceitos, políticas e modelo de análise. Ciênc Saude Colet. 2012; 17(11):2865-75.

8. Organização Pan-Americana de Saúde. A atenção à saúde coordenada pela APS: construindo as redes de atenção no SUS: contribuições para o debate. Brasília: OPAS; 2011.

9. Ministério da Saúde (BR). Secretaria-Executiva. Subsecretaria de Planejamento e Orçamento. Plano Nacional de Saúde - PNS: 2012-2015. Brasília: MS; 2011.

10. Cruz MM, Santos EM. Políticas de saúde. In: Matta GC, Pontes ALM, organizadores. Organização e operacionalização do sistema único de saúde. Rio de Janeiro: EPSJV/ Fiocruz; 2007.

11. Conselho Nacional de Secretários de Saúde (BR). Atenção primária e promoção da saúde. Brasília: CONASS; 2007.

12. Giovanella $L$, Mendonça $M H M$. Atenção primária à saúde. In: Giovanella $L$, Escorel S, Lobato LVC, Noronha JC, Carvalho AI, organizadores. Políticas e sistema de saúde no Brasil. Rio de Janeiro: Fiocruz; 2012.

13. Pierantoni CR. Reformas da saúde e recursos humanos: novos desafios $x$ velhos problemas [tese] [Internet]. Rio de Janeiro: Universidade do Estado do Rio de Janeiro; 2000. [citado 8 Ago 2013]. Disponível em: http://www.obsnetims.org.br/ uploaded/3_6_2013_0_Reformas_da_saude.pdf

14. Barthes R. Mitologias. Tradução de Rita Buongermino. 4a ed. Rio de Janeiro: Difel; 2009.

15. Ministério da Saúde (BR). Ministério da Educação. Ministério do Planejamento. Exposição de motivo 00024/2013 sobre a Medida Provisória 621 [Internet]. Brasília; 2014 [citado 8 Ago 2014]. Disponível em: http://www.planalto.gov.br/ccivil_03/_Ato20112014/2013/Mpv/mpv621.htm

16. Ministério da Educação (BR). Propostas de expansão de vagas do ensino médico nas Instituições Federais do Ensino Superior elaboradas pelo Grupo de Trabalho instituído pela Portaria n. 86, de 22 de março de 2012. Diário Oficial de União. 27 Mar 2012. 
17. Jornal Medicina. Brasília: Conselho Federal de Medicina; 2013. n. 216. Jan 2013. [internet] Acesso em mar 2015. Disponível em: http://www.flip3d.com.br/web/temp_ site/edicao-3d779cae2d46cf6a8a99a35ba4167977.pdf

18. Jornal Medicina. Brasília: Conselho Federal de Medicina; 2013. n. 217. Fev 2013. Acesso em mar 2015. Disponível em http://www.flip3d.com.br/web/pub/ $\mathrm{cfm} /$ ? numero $=217$ \&edicao $=1335$.

19. Jornal Medicina. Brasília: Conselho Federal de Medicina; 2013. n. 219. Abr 2013. [internet] Acesso em mar 2015. Disponível em http://www.flip3d.com.br/web/temp_ site/edicao-11c484ea9305ea4c7bb6b2e6d570d466.pdf

20. Jornal Medicina. Brasília: Conselho Federal de Medicina; 2013. n. 220. Mai 2013. [internet] Acesso em mar 2015. Disponível em: http://www.flip3d.com.br/web/temp_ site/edicao-231141b34c82aa95e48810a9d1b33a79.pdf

21. Jornal Medicina. Brasília: Conselho Federal de Medicina; 2013. n. 222. Jul 2013. [internet] Acesso em mar 2015. Disponível em http://www.flip3d.com.br/web/temp_site/ edicao-b60c5ab647a27045b462934977ccad9a.pdf

22. Jornal Medicina. Brasília: Conselho Federal de Medicina; 2013. n. 223. Ago 2013. [internet] Acesso em mar 2015. Disponível em http://www.flip3d.com.br/web/temp_site/ edicao-d8d31bd778da8bdd536187c36e48892b.pdf

23. Jornal Medicina. Brasília: Conselho Federal de Medicina; 2013. n. 224. Set 2013. [internet] Acesso em mar 2015. Disponível em: http://www.flip3d.com.br/web/temp_ site/edicao-ecd62de20ea67e1c2d933d311b08178a.pdf

24. Aciole GG. A Lei do Ato Médico: notas sobre suas influências para a educação médica. Rev Bras Educ Med. 2006; 30(1):47-54. http://dx.doi.org/10.1590/S010055022006000100008

25. Jornal Medicina. Brasília: Conselho Federal de Medicina; 2013. n. 225. Out 2013. [internet] Acesso em mar 2015. Disponível em: http://www.flip3d.com.br/web/temp_ site/edicao-f542eae1949358e25d8bfeefe5b199f1.pdf.

26. Jornal Medicina. Brasília: Conselho Federal de Medicina; 2013. n. 226. Nov 2013. [internet] Aceso em mar 2015. Disponível em http://www.flip3d.com.br/web/temp_site/ edicao-49ad23d1ec9fa4bd8d77d02681df5cfa.pdf.

27. Jornal Medicina. Brasília: Conselho Federal de Medicina; 2013. n. 229. Fev 2014. [internet] Acesso em mar 2015. Disponível em http://www.flip3d.com.br/web/temp_site/ edicao-4d8556695c262ab91ff51a943fdd6058.pdf.

28. Jornal Medicina. Brasília: Conselho Federal de Medicina; 2013. n. 234. Jul 2014. [internet] Acesso em mar 2015. Disponível em http://www.flip3d.com.br/web/temp_site/ edicao-a554f89dd61cabd2ff833d3468e2008a.pdf_.

29. Aciole GG. Depois da reforma: contribuição à crítica da Saúde coletiva. São Paulo: Hucitec; 2013. 
Aciole GG. El Proyecto Más Médicos para Brasil y la construcción de mitos: Una lectura bartheana. Interface (Botucatu). 2017; 21(Supl.1):1157-68.

El objetivo del proyecto Más Médicos para Brasil (PMMB) es proporcionar recursos humanos para el Sistema Brasileño de Salud, por medio de la mejora de la infraestructura de la red de salud, de la ampliación de las reformas educativas de los cursos de medicina y residencia médica y de la provisión de médicos para áreas vulnerables. La implantación del proyecto enfrentó reacciones contrarias a la propuesta, envolviendo principalmente a las instituciones médicas do país. Inspirados en el concepto de mito, realizamos una lectura de los discursos con que el Consejo Federal de Medicina sostuvo el debate, por medio del análisis del Jornal Medicina durante los primeros 24 meses de introducción del proyecto. El mito es un factor revelador de como las prácticas discursivas introducen en el imaginario colectivo alegorías que demarcan espacios ideológicos y permite analizar el proceso de disputa social y de las condiciones históricas de formulación e implantación de un programa gubernamental.

Palabras clave: Políticas. Planificación y administración en salud. Programas gubernamentales. Planes gubernamentales de Salud. Atención Primaria a la Salud. Sistema Brasileño de Salud. 